\title{
Influence des variants génétiques de la $\beta$-lactoglobuline et de la $\kappa$-caséine sur la composition du lait et son aptitude fromagère
}

\author{
V Rahali, JL Ménard * \\ ESA (École supérieure d'agriculture), 55 rue Rabelais, BP 748, 49007 Angers cedex, France
}

(Reçu le 26 juin 1989; accepté le 14 janvier 1991)

\begin{abstract}
Résumé - L'étude porte sur l'influence du polymorphisme génétique de la $\beta$-lactoglobuline $(\beta-L g)$ et de la $\kappa$-caséine $(\kappa-C n)$ sur la composition du lait et ses aptitudes à la coagulation et à la transformation fromagère. Quatre-vingt-trois fabrications de type Camembert au lait cru ont été réalisées au laboratoire à partir du lait de 230 vaches Pie Noire. Huit combinaisons génétiques de la $\beta$-Lg et de la $\kappa$-Cn ont été étudiées; les mesures ont porté sur la composition physico-chimique des laits de fabrication, caillés et sérums, les paramètres d'aptitude à la coagulation mesurés à l'aide d'un Formagraph et les bilans et pourcentages de récupération des matières lors des fabrications.

L'influence positive du génotype BB et de la $\beta$-Lg est mise en évidence essentiellement sur le taux de caséines du lait (+ $4,7 \%$ par rapport au génotype $A A)$ et sur la rétention des matières azotées totales dans le caillé $(+2,9 \%)$. Le génotype BB de la $\kappa$-Cn exerce des effets bénéfiques plus marqués, notamment sur le temps de coagulation des laits et la fermeté maximale des gels (respectivement $-24 \%$ et $+37 \%$ par rapport à l'homozygote AA), expliqués notamment par une composition protéique plus favorable. II en résulte une meilleure récupération des constituants du lait dans les caillés BB en $\kappa$-Cn. Le génotype $A B$ occupe une position intermédiaire.

L'analyse factorielle discriminante souligne le caractère additif de l'interaction entre les variants génétiques de la $\beta-\mathrm{Lg}$ et de la $\kappa-\mathrm{Cn}$. Un classement de qualité fromagère est proposé, le double homozygote $\mathrm{BB}$ en $\beta$ - Lg/BB en $\kappa-\mathrm{Cn}$ occupant la place la plus favorable.
\end{abstract}

variant génétique / $\kappa$-caséine / $\beta$-lactoglobuline / aptitude fromagère

Summary - Influence of genetic variants of $\beta$-lactoglobulin and $\kappa$-casein on milk composition and cheese-making capacity. The influence of genetic polymorphism of $\beta$-lactoglobulin $(\beta-\mathrm{Lg})$ and $\kappa$-casein $(\kappa-\mathrm{Cn})$ on milk composition and cheese-making capacity was investigated in 83 Camembert-type cheeses, issued from 230 Friesian cows' milk. Eight genetic combinations between $\beta-L g$ and $\kappa$-Cn were studied; the chemical composition of milks, curds and wheys was assessed, as well as the results and retention percentages of components during cheese processing; a Formagraph was used to determine coagulation properties. The positive influence of BB-genotype for $\beta$ - $\mathrm{Lg}$ is essentially shown in casein rate in milk ( $+4.7 \%$ compared to the AA-genotype) and total nitrogen retention in curd $(+2.9 \%)$. Beneficial effects of BB-genotype for $\kappa-C n$ are greater, especially as re-

\footnotetext{
- Adresse actuelle : ITEB (Institut technique de l'élevage bovin), 149 rue de Bercy, 75595 Paris cedex 12, France
} 
gards clotting time and maximum curd firmness (respectively $-24 \%$ and $+37 \%$ compared to the $A A$ genotype); these are explained, among other factors, by a more favourable proteic composition. The result is a better recovery of chemical components in curds characterized by the BB-genotype for $\mathrm{K}$ $\mathrm{Cn}$. The A-B-genotype is in between. Discriminating factorial analysis shows that the effects of genetic variants of $\beta-\mathrm{Lg}$ and $\mathrm{k}-\mathrm{Cn}$ are additive. Genetic combinations have been graded according to their cheese-making quality, the BB/BB genotype for both proteins ranking first.

\section{genetic variant / $\kappa$-casein / $\beta$-lactoglobulin / cheese-making capacity}

\section{INTRODUCTION}

Le polymorphisme génétique des protéines lajtières est un critère de variabilité de la composition du lait susceptible d'avoir des répercussions sur son aptitude à la transformation fromagère. Parmi ces protéines, les variants génétiques de la $\beta$ lactoglobuline $(\beta-\mathrm{Lg})$ et de la $\kappa$-caséine $(\kappa-$ $\mathrm{Cn}$ ) sont certainement ceux qui ont été les mieux étudiés. Ils sont présents sous 2 formes allèliques $A$ et $B$, bien connues sur le plan biochimique (Bell et al, 1968; Grosclaude et al, 1972). Selon la revue bibliographique de Grosclaude (1988), les fréquences de chaque allèle présentent en race Pie Noire (retenue pour l'expérimentation) un déséquilibre, faible pour la $\beta-\mathrm{Lg}$ (respectivement 56 et $44 \%$ pour les allèles A et B), plus important pour la $\kappa-C n$ (66 et $34 \%$ pour les allèles $A$ et $B$ ).

L'analyse des principaux travaux réalisés sur les conséquences de ce polymorphisme en transformation fromagère fait ressortir des points de convergence. Les laits contenant le variant $B$ de la $\beta$ - Lg sont caractérisés par des taux plus faibles de cette protéine (Mc Lean et al, 1984) mais aussi des taux plus élevés de caséine totale (Morini et al, 1982; Mc Lean et al, 1984; Mariani, 1985). Ce polymorphisme génétique se répercute sur l'aptitude fromagère des laits : en fabrication de Parmesan, Morini et al (1982) associent la présence de l'homozygote BB pour la $\beta-\mathrm{Lg}$ à une augmentation de rendement de $200 \mathrm{~g}$ de fromage aux $100 \mathrm{~kg}$ de lait par rapport à l'homozygote $\mathrm{AA}$.

Les variants génétiques de la $\kappa-\mathrm{Cn}$ exercent une influence encore plus grande sur les critères de composition et de coagulation du lait, ainsi que sur les rendements fromagers. Le polymorphisme génétique de la $\kappa-\mathrm{Cn}$ affecte de manière significative le taux de cette protéine, l'allèle $B$ étant le plus favorable, sans que le taux de caséines totales soit modifié (Mc Lean et al, 1984). D'autres auteurs associent le génotype $\mathrm{BB}$ de la $\kappa-\mathrm{Cn}$ à une teneur en protéines plus élevée ( $\mathrm{Ng}$-KwaiHang et al, 1984). Loisi et al (1973) et Mariani et al (1976) mettent en évidence la supériorité de ce même génotype sur le temps de coagulation du lait et la fermeté des gels obtenus. Sur des fabrications de Parmesan, une forte différence de rendement est constatée entre les génotypes AA et $\mathrm{BB}$ de la $\mathrm{\kappa}-\mathrm{Cn}$, au profit de l'homozygote BB (Mariani et al, 1976; Morini et al, 1979); en fabrication de Cheddar, Marziali et NgKwai-Hang (1986a) montrent également une supériorité du génotype BB de cette protéine sur le rendement fromager.

Les enjeux, tant scientifiques que technologiques et économiques, liés à l'estimation d'un effet variant sur le rendement fromager incitent à la mise en œuvre d'expérimentations visant à accroître et élargir le champ des connaissances sur ce thème. Or, la plupart des études ont été conduites en utilisant des technologies de 
fabrication fromagère de type pâtes pressées cuites ou non cuites. Les effets du polymorphisme génétique en technologie pâte molle, catégorie de fromages qui représentait $31,3 \%$ de la production française en 1988 (CNIEL, 1990), sont par contre peu connus. II nous paraissait donc opportun de mesurer l'impact d'un effet variant sur la composition du lait utilisé en fabrication de type Camembert, en évaluant l'influence des variants génétiques $A$ et $B$ de la $\beta$ - Lg et de la $\mathrm{k}-\mathrm{Cn}$ à 3 niveaux : 1) composition physico-chimique fine des laits de fabrication (en privilégiant la fraction azotée; 2) paramètres d'aptitude à la coagulation de ces mêmes laits; 3 ) bilans de fabrications fromagères de type $\mathrm{Ca}$ membert au lait cru, réalisées au laboratoire.

Une première approche des résultats obtenus nous a permis de mesurer les effets des variants génétiques propres à chacune des protéines étudiées; nous avons complété le traitement des données en étudiant l'interaction des variants génétiques des 2 protéines par une analyse factorielle discriminante (AFD).

\section{MATÉRIEL ET MÉTHODES}

\section{Détermination des génotypes des vaches}

L'identification des variants génétiques des 2 protéines étudiées a été réalisée par électrophorèse en gel d'amidon-urée à $\mathrm{pH}=8,6$ selon la technique de Wake et Baldwin (1961), les échantillons de caséine isoélectrique et de protéines sériques étant préparés selon la méthode d'Aschaffenburg et Drewry (1959).

\section{Méthodologie de l'échantillonnage des animaux}

L'expérimentation a été conduite en race Pie Noire. Afin d'augmenter la fréquence des allèles rares (allèle $B$ de la $\kappa-C n$ notamment), les taureaux hétérozygotes $A B-A B$ (respectivement $\beta$ $\mathrm{Lg}-\kappa-\mathrm{Cn}$ ) ont été recherchés. La détermination génotypique des 24 taureaux les plus utilisés dans notre zone d'étude (région Pays-de-laLoire) et ayant déjà des filles en lactation a donc été réalisée à partir de l'analyse électrophorétique des laits d'une dizaine de couples mère-fille par taureau, soit 340 vaches au total. Connaissant le génotype des filles et celui de leur mère, il était possible de reconstituer celui du père (transmission mendélienne du caractère). Trois taureaux hétérozygotes $A B-A B$ ont pu ainsi être retenus pour l'expérimentation. L'identification génétique de 779 filles de ces 3 taureaux, réparties sur 92 élevages, a ensuite été réalisée; l'analyse de leur répartition dans 8 couples de combinaisons génétiques (AA-AA; $A A-A B ; A A-$ $B B ; A B-A A ; A B-B B ; B B-A A, B B-A B ; B B-B B$ ) a finalement servi de base à la constitution de l'échantillon final (voir partie Résultats). La $9^{\mathrm{e}}$ combinaison génétique (double hétérozygote $A B-A B$ ) n'a pas été étudiée.

\section{Méthodologie de fabrication fromagère}

Lors de la traite du soir, des échantillons de lait de chaque vache retenue pour l'étude ont été prélevés; afin de limiter l'influence des laits individuels sur les fabrications fromagères, des mélanges de 2 à 4 laits individuels génétiquement identiques ont été réalisés, puis conservés à $+4^{\circ} \mathrm{C}$ pendant $10 \mathrm{~h}$. Chaque lait de mélange était alors transformé en fromage de type $\mathrm{Ca}$ membert au lait cru (jusqu'au stade caillé égoutté), selon une méthodologie standardisée adaptable à l'échelle du laboratoire et mise au point à la station de recherches laitières de I'INRA Jouy-en-Josas (Vassal, 1986, communication personnelle). Mille grammes de lait cru de mé- 
lange (équivalent à une unité de fabrication) étaient mis à maturer à $33-34{ }^{\circ} \mathrm{C}$ en présence de levains concentrés lyophilisés "MA 100" (EZAL, Lacto-Labo, France). Ces levains sont constitués d'un mélange acidifiant à $80 \%$ de Streptococcus lactis et cremoris et $20 \%$ de Streptococcus diacetylactis. L'ensemencement était réalisé à un taux de 2 unités $/ 100$ I de lait. La quantité de lait mise en œuvre, inférieure de moitié à celle d'un Camembert traditionnel, nous permettait d'obtenir un fromage de diamètre équivalent, mais dont l'épaisseur réduite nous affranchissait de l'étape de retournement en cours d'égouttage. Les levains étaient préalablement remis en culture à une concentration de $2 \mathrm{~g} / \mathrm{l}$ dans une eau peptonée à $30^{\circ} \mathrm{C}$ pendant $10 \mathrm{~min}$. Le lait de fabrication était alors ensemencé avec $10 \mathrm{ml}$ de bouillon peptoné, et maintenu en cuve recouverte pour limiter au maximum les pertes sous forme d'évaporation. Après une maturation courte ( $30 \mathrm{~min})$, correspondant à une baisse de $\mathrm{pH}$ du lait de 0,1 unité, l'emprésurage était effectué, à $33-34^{\circ} \mathrm{C}$ et $\mathrm{pH}$ $=6,5$ avec $0,4 \mathrm{ml} / \mathrm{kg}$ de lait d'extrait de présure Granday (Granday-Roger, Sanofi, France) à $520 \mathrm{mg}$ de chymosine par litre d'extrait.

Une heure et demie après l'emprésurage, le caillé était découpé en cubes de $1 \mathrm{~cm}$ de côté. La mise en moule avait lieu $30 \mathrm{~min}$ après le découpage, l'égouttage étant réalisé dans une enceinte prévue à cet effet, maintenue à $25 \pm$ $0,5^{\circ} \mathrm{C}$; le sérum était recueilli, hors de l'enceinte, en flacon immergé dans la glace.

Le démoulage était effectué après 19 h 30 d'égouttage et était immédiatement suivi de la pesée des produits (caillé "24 h» et lactosérum).

Pour chaque lait de petit mélange correspondant à une combinaison génétique ( $\beta-\mathrm{Lg}, \kappa-\mathrm{Cn})$, 2 fabrications fromagères ont été réalisées (correspondant à un échantillon et son double). Les fabrications se sont déroulées pendant 12 semaines consécutives (de mai à juillet 1986) à raison d'un fromage (et son double) par combinaison génétique et par semaine.

\section{Mesure des paramètres de coagulation des laits et étude de leur répétabilité}

Les paramètres de coagulation des laits de petit mélange, conservés à $+4{ }^{\circ} \mathrm{C}$ pendant $20 \mathrm{~h}$ après le prélèvement, ont été mesurés à l'aide d'un appareil Formagraph (Foss-Electric); $10 \mathrm{ml}$ de lait cru $(\mathrm{pH}$ non standardisé et sans rééquilibrage minéral) étaient portés à une température de $40{ }^{\circ} \mathrm{C}$, puis emprésurés avec une solution d'extrait de présure Granday ( $5 \mu \mathrm{l} / 10 \mathrm{ml}$ de lait); à partir du tracé en diapason obtenu (Alais, 1984), les critères suivants ont été appréciés :

- le temps de coagulation du lait;

- le temps de raffermissement du gel (temps pour que le caillé présente des propriétés mécaniques telles que l'écartement entre les 2 branches du diapason soit de $20 \mathrm{~mm}$ );

- la fermeté maximale du gel : écartement maximal (en mm) entre les deux branches du diapason;

- le temps pour afteindre la fermeté maximale.

Les mesures au Formagraph ont été réalisées en double pour chaque échantillon de lait. La répétabilité des résultats a été évaluée selon la méthode proposée par Grappin (1976). Le temps de coagulation, le temps de rafermissement et la fermeté maximale du gel, ont un écart type de répétabilité respectivement de 0,92 min, 1,60 min et 2,14 mm (tableau I). Dans des conditions différentes (16 analyses d'un même lait), I'Institut Technique du Gruyère (ITG, 1984), obtient des écarts types de répétabilité un peu plus faibles : 0,54 min pour le temps de coagulation, $1,65 \mathrm{~mm}$ pour la fermeté du gel $20 \mathrm{~min}$ après la coagulation. Dans l'analyse de nos résultats, la moyenne des 2 répétitions sera prise en compte afin d'atténuer la moins bonne répétabilité des critères obtenus au Formagraph.

\section{Analyses physico-chimiques des laits, caillés et sérums}

\section{Laits de petit mélange}

Immédiatement après constitution de chaque lait de petit mélange, une fraction était prélevée en vue des analyses physico-chimiques :

- masse volumique (norme AFNOR V04-204); - extrait sec total (EST, norme AFNOR V04207);

- numération microbienne (méthode Thomson) et comptage cellulaire (méthode de Tolle, décrite par Grappin et Jeunet, 1971); 
Tableau I. Répétabilité des mesures de coagulation du lait au Formagraph. Repeatability of coagulation properties measured on Formagraph.

\begin{tabular}{|l|c|c|c|c|c|}
\cline { 2 - 6 } \multicolumn{1}{c|}{} & $\begin{array}{l}\text { Nombre } \\
\text { j'échantillons }\end{array}$ & Moyenne & $\begin{array}{c}\text { SCE (1) } \\
\text { "échantillon" }\end{array}$ & $\begin{array}{c}\text { SCE } \\
\text { "répétition" }\end{array}$ & $\begin{array}{c}\text { Ecart-type } \\
\text { pe répétabilite }\end{array}$ \\
\hline - Temps de coagulation (en min) & 83 & 13,2 & 1206,75 & 70,94 & 0,92 \\
- Temps de raffermissement (en min) & 83 & 9,7 & 2312,55 & 211,53 & 1,60 \\
$\begin{array}{l}\text { - Temps pour atteindre la fermeté } \\
\text { maximale (en min) }\end{array}$ & 83 & 32,8 & 4498,66 & 2350,18 & 5,32 \\
- Fermeté maximale (en mm) & 83 & 37,1 & 4120,24 & 381,44 & 2,14 \\
\hline
\end{tabular}

(1) SCE : Somme des carrés des écarts.

(1) SCE : Sum of the squared deviations.

- matière grasse : méthode à l'infrarouge (appareil Milkoscan 605);

- matières protéiques : méthode au noir Amido (norme AFNOR V04-216);

- fractions azotées : matières azotées totales (NT) et matières azotées solubles ou matières azotées non caséiniques (NS) après précipitation acide à $\mathrm{pH}=4,6$ dosées par la méthode macro-Kjeldahl (norme AFNOR V04-211); les matières azotées caséiniques (NC) sont obtenues par la différence NT-NS, en tenant compte du volume occupé par le précipité caséinique (coefficient correctif égal à 0,994, AFNOR-ITSV, 1986);

- taux de calcium total : méthode par spectrométrie d'émission de flamme (norme AFNOR V04-355).

\section{Caillés et sérums}

Les caillés et sérums étaient pesés dès la fin de l'égouttage et les analyses physico-chimiques réalisées le jour même :

- extrait sec total (EST) des caillés par étuvage à $102{ }^{\circ} \mathrm{C}$ jusqu'à poids constant et extrait sec total des sérums selon la norme AFNOR V04207;
- matière grasse des caillés par la méthode van Gulick (norme AFNOR V04-287), et des sérums par la méthode Gerber «lait écrémé» (norme AFNOR V04-210);

- fractions azotées (NT et NS) des caillés et sérums par la méthode macro-Kjeldahl; la remise en suspension du caillé était réalisée selon la technique développée par Gripon et al (1975);

- taux de calcium des sérums par spectrométrie d'émission de flamme (norme AFNOR V04355).

Les analyses ont été réalisées par le laboratoire interprofessionnel Unilab (49, Angers); seules les fractions azotées du caillé ont été dosées au laboratoire de I'ESA.

\section{Mode d'exploitation des résultats}

Les résultats concernant les critères de composition physico-chimique des laits, caillés et sérums et les paramètres de coagulation constituent des variables brutes. D'autres variables, calculées, ont été prises en compte :

- l'extrait sec dégraissé (ESD), différence entre EST et matières grasse; 
- le rapport gras/sec (G/S) résultant des teneurs en matière grasse et matières azotées des laits, non standardisées dans le cadre de notre étude;

- l'humidité du fromage dégraissé (HFD) qui permet d'apprécier l'aptitude à la synérèse lors de l'égouttage des caillés (Mietton, 1987)

- les bilans “entrées-sorties" (Mietton, 1986) qui permettent d'évaluer les pertes au cours du processus de fabrication soit sous forme d'évaporation, soit sous forme de caillé sur les grilles d'égouttage (avec pertes de constituants);

- les pourcentages de récupération des constituants du lait dans le caillé (Mietton, 1986) pour confirmer les différences de composition des produits et les pertes sur les grilles d'égouttage.

L'analyse statistique a été réalisée sur un modèle d'échantillonnage déséquilibré (génotype double hétérozygote non pris en compte, nombre d'observations variable selon les génotypes (tableau IV). Pour chaque variable, une comparaison de moyenne (test de Student) a été réalisée entre les génotypes $A A, A B, B B$ pris 2 à 2 (échantillons indépendants) et ceci pour chacune des protéines. L'interaction entres les variants génétiques des 2 protéines a été appréhendée par une analyse factorielle discriminante.

\section{RÉSULTATS - DISCUSSION}

\section{Caractéristiques générales de l'échantillon final}

Les 779 vaches issues des 3 taureaux double hétérozygotes se répartissent de façon très inégale entre les différentes combinaisons génétiques de la $\beta$ - $\mathrm{Lg}$ et de la $\kappa-C n$ (tableau II), le génotype BB pour la $\kappa$-Cn étant en particulier plus faiblement représenté $(11,4 \%)$. Dans cette population, nous obtenons des fréquences alléliques brutes de 0,45 et 0,55 pour les allèles $A$ et $B$ de la $\beta$ - $L$ g et de 0,63 et 0,37 pour les allèles $A$ et $B$ de la $\kappa-C n$; les fréquences correspondant à la génération précédente sont respectivement égales à 0,40 et 0,60

Tableau II. Répartition des génotypes de la $\beta$ - $\mathrm{Lg}$ et de la $\kappa$-Cn en $\%$ dans la population des 779 vaches issues des 3 taureaux hétérozygotes (Nombre d'individus).

Percentage of $\beta-\mathrm{Lg}$ and $\kappa$-Cn genotypes among the 779 cows issued from the 3 heterozygous bulls (No of individuals).

\begin{tabular}{|c|c|c|c|c|c|c|c|c|c|}
\hline & & \multicolumn{6}{|c|}{$\kappa-C n$} & \multirow{2}{*}{\multicolumn{2}{|c|}{ TOTAL }} \\
\hline & & \multicolumn{2}{|r|}{ AA } & \multicolumn{2}{|c|}{$A B$} & \multicolumn{2}{|c|}{ BB } & & \\
\hline \multirow{3}{*}{$B-\operatorname{Lg}$} & AA & 7,1 & (55) & 10,1 & (79) & 2,3 & (18) & 19,5 & (152) \\
\hline & $A B$ & 19,5 & (152) & 25,7 & (200) & 5,8 & (45) & 51 & (397) \\
\hline & BB & 10,4 & (81) & 15,8 & (123) & 3,3 & (26) & 29,5 & (230) \\
\hline \multicolumn{2}{|l|}{ TOTAL } & 37 & (288) & 51,6 & (402) & 11,4 & (89) & 100 & (779) \\
\hline
\end{tabular}


pour la $\beta$-Lg et 0,75 et 0,25 pour la $\kappa-C n$. Cette répartition est en accord avec celle recensée par d'autres auteurs en race frisonne, et notamment celle de $\mathrm{Ng}$-KwaiHang et al (1984), qui sur plus de 2000 animaux, obtiennent des fréquences quasiment identiques à nos fréquences corrigées $(0,39$ et 0,61 pour la $\beta$-Lg; 0,74 et $0,26$ pour la $\kappa-\mathrm{Cn})$. À partir de taureaux hétérozygotes, nous augmentons la fréquence de l'allèle le plus rare (allèle $B$ de la $\kappa-(n)$ de $48 \%$ par rapport à la génération précédente.

L'échantillon final de travail a été sélectionné à partir de la distribution obtenue. Le groupe génotypique le moins représenté (AA- $\beta-L g / B B-\kappa-C n)$ a déterminé :

- le nombre moyen d'animaux de chaque génotype à utiliser pour réaliser l'ensemble des fabrications fromagères;
- les valeurs des caractéristiques liées à l'animal retenu (effet père, numéro de lactation, stade de lactation), pour constituer un échantillon homogène.

Nous avons donc finalement travaillé à partir d'un groupe de 230 vaches provenant de 71 élevages et réparties entre les 8 combinaisons génétiques étudiées. Cet échantillon est caractérisé par (tableau III) :

- une bonne répartition de la descendance des 3 taureaux hétérozygotes entre les 8 groupes;

- un nombre de lactations proche de 2 pour l'ensemble de la population avec cependant une différence significative (à 5\%) entre les résultats obtenus pour les génotypes AA et BB de la $\beta$-Lg;

- un stade de lactation assez avancé (proche de 7 mois en moyenne), compte

Tableau III. Caractéristiques de l'échantillon final.

Final sampling characteristics.

\begin{tabular}{|c|c|c|c|c|c|c|}
\hline & \multicolumn{3}{|c|}{$\beta$ - Lactoglobuline } & \multicolumn{3}{|c|}{$\kappa$-Caséine } \\
\hline & génotype $\mathrm{AA}$ & Génotype $A B$ & génotype BB & génotype AA & génotype AB & génotype BB \\
\hline $\begin{array}{l}\text { Répartition des } \\
\text { pères: }\end{array}$ & & & & & & \\
\hline $\begin{array}{l}\text { - taureau } n^{\circ} 1 \\
\text { - taureau } n^{\circ} 2 \\
\text { - taureau } n^{\circ} 3\end{array}$ & $\begin{array}{l}16^{(1)} \\
48 \\
8\end{array}$ & $\begin{array}{l}18 \\
34 \\
16\end{array}$ & $\begin{array}{l}16 \\
58 \\
16\end{array}$ & $\begin{array}{l}22 \\
53 \\
17\end{array}$ & $\begin{array}{l}12 \\
46 \\
11\end{array}$ & $\begin{array}{l}16 \\
41 \\
12\end{array}$ \\
\hline $\begin{array}{l}\text { Répartition des } \\
230 \text { vaches de } \\
\text { l'échantillon }\end{array}$ & $72^{(1)}$ & 68 & 90 & 92 & 69 & 69 \\
\hline Nombre de lactation & $2,21 \pm 0,13^{(2)}$ & $1,96 \pm 0,09$ & $1,84 \pm 0,08$ & $2,04 \pm 0$ & $1,99 \pm 0,10$ & $1,93 \pm 0,09$ \\
\hline $\begin{array}{l}\text { Stade de lactation } \\
\text { (en mois) }\end{array}$ & $7,03 \pm 0,27^{(2)}$ & $6,75 \pm 0,26$ & $6,89 \pm 0,23$ & $6,96 \pm 0,22$ & $6,48 \pm 0,28$ & $7,22 \pm 0,24$ \\
\hline
\end{tabular}

(1) : Nombre de vaches; (2) Moyenne \pm écart-type.

(1) : No of cows; (2) Mean \pm standard deviation. 
Tableau IV. Répartition des fabrications fromagères (Nombre de vaches prélevées).

Cheese making distribution (No of cows).

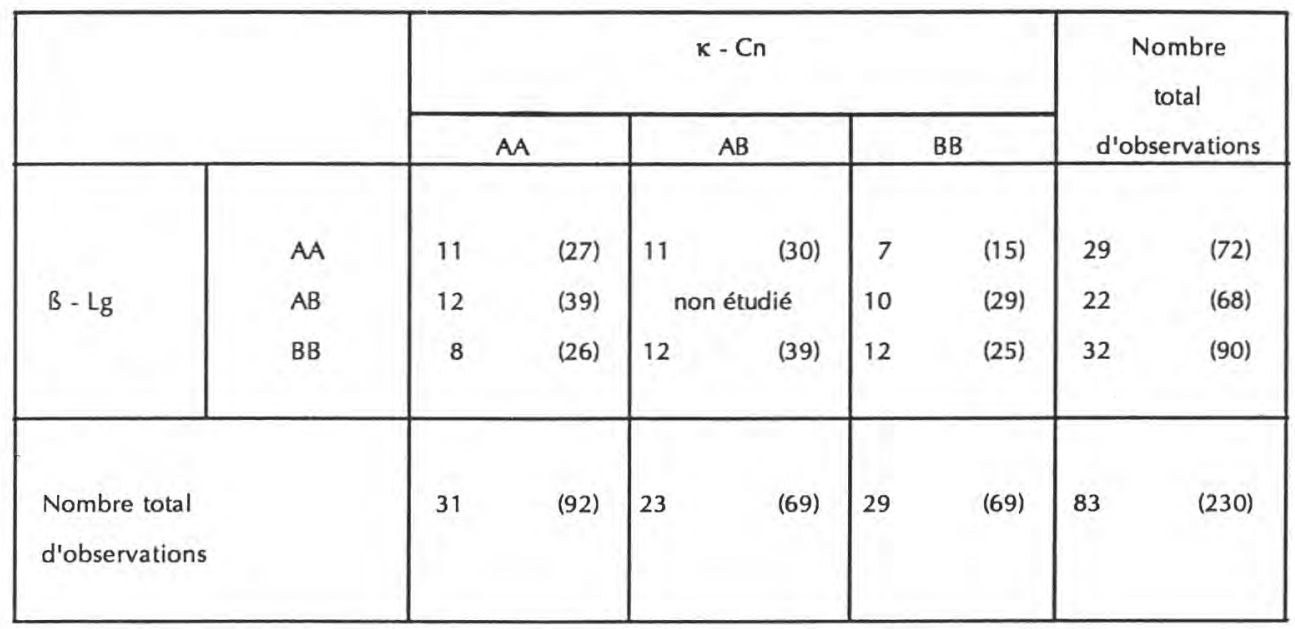

tenu de la période d'expérimentation (mai à juillet).

Les 230 laits ont été répartis en 83 fabrications fromagères (tableau IV); les contrôles de contamination microbienne et de numération cellulaire effectués sur chaque lait de petit mélange (2-4 laits individuels par fabrication) ont permis d'éliminer les échantillons contenant plus de 300000 germes totaux $/ \mathrm{ml}$ et plus de 800000 cellules/ml.

\section{Influence des variants génétiques de la $\beta$-lactoglobuline}

\section{Composition des laits et aptitude à la coagulation (tableau V)}

Quel que soit le génotype de la $\beta$ - Lg considéré, les matières azotées totales (NT) et les matières protéiques des laits ne sont pas significativement différentes, contrairement aux teneurs en azote non caséinique (NS) : ainsi, les laits de génotype AA sont significativement plus riches que les laits BB (+0,94 g/kg, soit $+12,5 \%)$; les laits AB occupent une position intermédiaire, mais plus proche cependant des laits BB. Ces différences se répercutent logiquement au niveau des teneurs en caséines avec un degré de signification moindre, et au profit du génotype $B B(+1,2 \mathrm{~g} / \mathrm{kg}$, soit $+4,7 \%$ par rapport à l'homozygote $A A)$; ce résultat est confirmé et amplifié dans le rapport caséines/NT qui augmente de façon très significative en présence de l'allèle $B(A A<$ $\mathrm{AB}<\mathrm{BB}$ ).

Ces résultats sur les matières azotées du lait vont dans le même sens que ceux obtenus par d'autres auteurs : Mc Lean et al (1984) ont montré que la présence du variant $A$ de la $\beta$ - Lg augmentait la syn- 
Tableau V. Comparaison des génotypes de la $\beta$-lactoglobuline et influence sur les paramètres de composition du lait et d'aptitude à la coagulation (moyenne \pm écart type la moyenne).

Comparison between $\beta$-lactoglobulin genotypes and influence on milk composition and coagulation properties (mean \pm standard deviation from the mean).

\begin{tabular}{|c|c|c|c|c|c|c|}
\hline & \multicolumn{3}{|c|}{ B-lactoglobuline } & \multicolumn{3}{|c|}{$\begin{array}{l}\text { Test de comparaison des } \\
\text { moyennes (1) }\end{array}$} \\
\hline & $\begin{array}{l}\text { genotype AA } \\
\text { (29 observ) }\end{array}$ & $\begin{array}{l}\text { génotype } A B \\
\text { (22 observ) }\end{array}$ & $\begin{array}{l}\text { génotype BB } \\
\text { (32 observ) }\end{array}$ & $A A / A B$ & $A B / B B$ & $\mathrm{AA} / \mathrm{BB}$ \\
\hline $\begin{array}{l}\text { Composition } \\
\text { azotée du lait }\end{array}$ & & & & & & \\
\hline - NT $\quad(\mathrm{g} / \mathrm{kg})$ & $33,31 \pm 0,38$ & $33,08 \pm 0,46$ & $33,58 \pm 0,34$ & l & 1 & l \\
\hline $\begin{array}{r}\text { - Matières protéiques } \\
(\mathrm{g} / \mathrm{kg})\end{array}$ & $31,53 \pm 0,37$ & $31,02 \pm 0,46$ & $31,47 \pm 0,34$ & I & 1 & 1 \\
\hline - Caséines $\quad(\mathrm{g} / \mathrm{kg})$ & $25,78 \pm 0,35$ & $26,24 \pm 0,45$ & $26,98 \pm 0,31$ & 1 & 1 & * \\
\hline - NS $\quad(g / k g)$ & $7,53 \pm 0,14$ & $6,84 \pm 0,08$ & $6,59 \pm 0,08$ & **** & * & $* * *$ \\
\hline$-\frac{\text { Caséines }}{\text { NT }} \quad(\%)$ & $77,36 \pm 0,39$ & $79,26 \pm 0,32$ & $80,34 \pm 0,22$ & **** & ** & **** \\
\hline $\begin{array}{l}\text { Autres paramètres } \\
\text { de composition }\end{array}$ & & & & & & \\
\hline - Matière grasse $(\mathrm{g} / \mathrm{kg})$ & $40,79 \pm 0,97$ & $38,57 \pm 0,94$ & $41,30 \pm 0,92$ & 1 & * & 1 \\
\hline - Calcium total $(\mathrm{g} / \mathrm{kg})$ & $1,32 \pm 0,03$ & $1,28 \pm 0,03$ & $1,34 \pm 0,04$ & 1 & I & 1 \\
\hline - EST & $128,33 \pm 1,24$ & $125,83 \pm 1,18$ & $129,62 \pm 1,08$ & 1 & * & 1 \\
\hline$-p H$ & $6,61 \pm 0,01$ & $6,62 \pm 0,01$ & $6,61 \pm 0,01$ & ! & 1 & 1 \\
\hline$\frac{\text { Parametres de }}{\text { coagulation }}$ & & & & & & \\
\hline $\begin{array}{r}\text { - temps de coagulatior } \\
(\min )\end{array}$ & $12,84 \pm 0,78$ & $12,83 \pm 0,81$ & $12,84 \pm 0,60$ & 1 & 1 & 1 \\
\hline $\begin{array}{c}\text { - temps de rafermisse- } \\
\text { ment du gel }(\min )\end{array}$ & $9,25 \pm 0,91$ & $10,12 \pm 1,59$ & $8,40 \pm 0,66$ & I & 1 & 1 \\
\hline $\begin{array}{r}\text { - temps pour atteindre } \\
\text { la fermeté maximale } \\
\text { (min) }\end{array}$ & $31,46 \pm 1,53$ & $32,96 \pm 2,11$ & $33,78 \pm 1,49$ & l & 1 & 1 \\
\hline $\begin{array}{l}\text { - fermeté maximale } \\
\text { du gel }(\mathrm{mm})\end{array}$ & $36,58 \pm 1,19$ & $37,05 \pm 2,01$ & $39,19 \pm 1,14$ & 1 & 1 & 1 \\
\hline
\end{tabular}

(1) /: non significatif $(P>5 \%) ;{ }^{*}$; significatif à $5 \% ;{ }^{* *}$ : significatif à $1 \%$; ${ }^{* * *}$ : significatif à $0,1 \%$.

(1) /: non-significant $(P>5 \%) ;:$ : significant at $5 \%$; ** : significant at $1 \% ;{ }^{* * *}$ : significant at $0.1 \%$.

thèse de cette protéine; la $\beta-\mathrm{Lg}$ étant la protéine principale du lactosérum, les laits possédant le génotype AA présentent par conséquent un taux d'azote non caséinique plus élevé, vraisemblablement dû à l'augmentation du taux de $\beta-\mathrm{Lg}$ (non mesuré dans notre étude) présent dans ces laits. L'influence des variants de la $\beta-\mathrm{Lg}$ sur le taux de caséines que nous observons est à rapprocher des mêmes travaux 
de Mc Lean et al (1984) et de ceux de Mariani et al (1979); les laits BB en $\beta-\mathrm{Lg}$ sont significativement plus riches en caséines totales, sans pour autant que le taux de matières azotées totales soit modifié (différences non significatives entre les génotypes). L'homozygote BB constitue de ce fait le génotype le plus favorable à la composition protéique des laits (taux de caséines supérieur) en vue de leur valorisation fromagère.

Les résultats obtenus pour la matière grasse et l'extrait sec total (EST) sont plus difficilement interprétables; si l'on observe un écart non significatif des taux de matière grasse entre les génotypes $A A$ et $B B$, la position non intermédiaire de l'hétérozygote $A B$ semble surprenante. Ce résultat est contradictoire avec celui obtenu par Mc Lean et al (1984), qui mettent en évidence un effet positif des génotypes $A B$ et $B B$ de cette protéine sur le taux de matière grasse. Entre les homozygotes AA et BB, nous observons seulement une tendance à l'augmentation de ce taux, tout comme $\mathrm{Ng}-$ Kwai-Hang et al (1984), qui ont chiffré celle-ci à $0,04 \%$ sur des laits de race Braunvieh. Toutefois, les différences de faible amplitude entre génotypes nous incitent à conclure à une influence négligeable du génotype de la $\beta$ - Lg sur le taux butyreux.

Partant de laits à $\mathrm{pH}$ et taux de calcium total non significativement différents, les variations de composition azotée des laits (caséines et rapport caséines/NT) ne se répercutent pas de façon significative sur les paramètres d'aptitude à la coagulation mesurés. Nous observons cependant assez logiquement une tendance à l'augmentation de la fermeté maximale des gels en présence de l'allèle $B$ de la $\beta$ - $\mathrm{Lg}$ $(A A<A B<B B)$. D'autres auteurs ont montré des différences significatives en faveur du variant $B$, attribuées à une concentra- tion en caséines supérieure pour les laits possédant cet allèle (Feagan et al, 1972).

\section{Résultats des fabrications fromagères (tableau VI)}

Le poids moyen des caillés de génotype BB est légèrement plus élevé, bien que de manière non significative, par rapport aux génotypes $A A$ et $A B$ (respectivement $+6,38 \mathrm{~g}(+3,1 \%)$ et $+6,59 \mathrm{~g}(+3,2 \%))$. Ce résultat se répercute, en sens inverse, sur les poids de lactosérum $(A A \approx A B>B B$, non significatif).

La composition des produits (caillé et lactosérum) est directement influencée par celle du lait cru de départ. La présence du variant $\mathrm{B}$ entraîne un plus fort rapport caséine/NT du lait cru ce qui explique la plus faible teneur en azote total et en azote non caséinique du lactọsérum $(A A>A B \approx B B)$, ainsi qu'une teneur moindre en azote non caséinique du caillé $(A A>A B \approx B B$ ). Ces résultats confirment donc sur les produits de fabrication fromagère l'intérêt du génotype BB sur les fractions azotées.

D'autre part, la teneur en matière grasse plus faible pour les laits de génotype $A B$ se répercute de manière significative sur la concentration en matière grasse et en extrait sec total des caillés $(A A \approx B B$ $>A B$ ). La teneur en extrait sec dégraissé n'est significativement pas différente entre les génotypes, ce qui confirme l'effet de la matière grasse sur l'extrait sec total. Malgré ces différences, le rapport gras/sec des caillés n'est pas influencé de manière significative par les variants génétiques de la $\beta$-Lg.

Aucune différence significative n'a été mise en évidence entre les génotypes sur l'aptitude à l'égouttage des caillés (HFD équivalents), et la capacité de rétention des matières grasses dans le caillé (te- 
Tableau VI. Influence des variants génétiques de la $\beta$-lactoglobuline sur les résultats des fabrications fromagères (moyenne \pm écart type à la moyenne).

Influence of genetic variants of $\beta$-lactoglobulin on cheese-making results (mean \pm standard deviation from the mean).

\begin{tabular}{|c|c|c|c|c|c|c|}
\hline & \multicolumn{3}{|c|}{$\beta$ - lactoglobuline } & \multicolumn{3}{|c|}{$\begin{array}{l}\text { Test de comparaison des } \\
\text { moyennes (1) }\end{array}$} \\
\hline & $\begin{array}{l}\text { génotype } A A \\
\text { ( } 29 \text { observ ) }\end{array}$ & $\begin{array}{l}\text { génotype } A B \\
(22 \text { observ ) }\end{array}$ & $\begin{array}{l}\text { génotype BB } \\
\text { ( } 32 \text { observ ) }\end{array}$ & $A A / A B$ & $A B / B B$ & $\mathrm{AA} / \mathrm{BB}$ \\
\hline 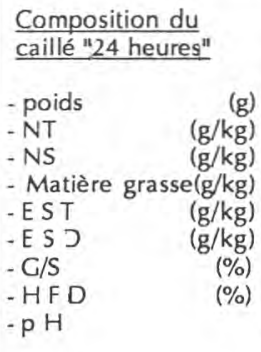 & $\begin{array}{r}204,82 \pm 2,99 \\
119,93 \pm 1,70 \\
9,00 \pm 0,19 \\
191,14 \pm 3,44 \\
354,61 \pm 3,41 \\
163,48 \pm 1,61 \\
53,81 \pm 0,55 \\
79,79 \pm 0,20 \\
4,47 \pm 0,03\end{array}$ & $\begin{array}{r}204,61 \pm 3,44 \\
122,15 \pm 1,65 \\
8,25 \pm 0,15 \\
180,90 \pm 3,27 \\
346,66 \pm 2,43 \\
165,73 \pm 1,63 \\
52,11 \pm 0,66 \\
79,77 \pm 0,16 \\
4,46 \pm 0,05\end{array}$ & $\begin{array}{r}211,20 \pm 2,50 \\
121,84 \pm 1,35 \\
8,15 \pm 0,13 \\
190,26 \pm 3,43 \\
356,34 \pm 2,73 \\
166,08 \pm 1,67 \\
53,30 \pm 0,61 \\
79,49 \pm 0,17 \\
4,48 \pm 0,03\end{array}$ & $\begin{array}{l}1 \\
1 \\
* * \\
* \\
1 \\
1 \\
1 \\
1 \\
1\end{array}$ & $\begin{array}{l}1 \\
1 \\
1 \\
1 \\
* \\
1 \\
1 \\
1 \\
1\end{array}$ & $\begin{array}{l}1 \\
1 \\
* * * \\
1 \\
1 \\
1 \\
1 \\
1 \\
1\end{array}$ \\
\hline $\begin{array}{l}\text { Composition du } \\
\text { lactosérum }\end{array}$ & & & & & & \\
\hline $\begin{array}{lr}\text { - poids } & (\mathrm{g}) \\
\text { - NT } & (\mathrm{g} / \mathrm{kg}) \\
\text { - NS } & (\mathrm{g} / \mathrm{kg}) \\
\text { - Matière grasse }(\mathrm{g} / \mathrm{kg}) \\
\text { - Calcium total }(\mathrm{g} / \mathrm{kg}) \\
\text { - E.S.T. } & (\mathrm{g} / \mathrm{kg}) \\
\text { - E.S.D. } & (\mathrm{g} / \mathrm{kg})\end{array}$ & $\begin{array}{r}790,97 \pm 2,90 \\
10,53 \pm 0,17 \\
10,31 \pm 0,18 \\
0,94 \pm 0,08 \\
1,03 \pm 0,03 \\
68,19 \pm 0,30 \\
67,25 \pm 0,30\end{array}$ & $\begin{array}{r}790,92 \pm 3,06 \\
9,72 \pm 0,07 \\
9,52 \pm 0,08 \\
0,93 \pm 0,09 \\
0,99 \pm 0,02 \\
67,44 \pm 0,29 \\
66,51 \pm 0,30\end{array}$ & $\begin{array}{r}784,83 \pm 2,68 \\
9,55 \pm 0,10 \\
9,33 \pm 0,10 \\
0,94 \pm 0,08 \\
1,05 \pm 0,04 \\
67,61 \pm 0,29 \\
66,67 \pm 0,28\end{array}$ & $\begin{array}{c}\text { I } \\
* * * \\
* * * \\
! \\
! \\
!\end{array}$ & $\begin{array}{l}1 \\
1 \\
1 \\
1 \\
1 \\
1 \\
1\end{array}$ & $\begin{array}{c}1 \\
* * * \\
* * * \\
1 \\
1 \\
1 \\
1\end{array}$ \\
\hline 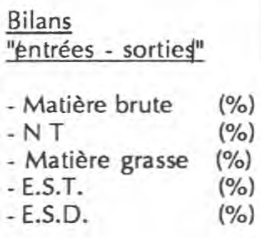 & $\begin{array}{l}-1,62 \pm 0,04 \\
-1,47 \pm 0,31 \\
-2,12 \pm 0,48 \\
-1,36 \pm 0,19 \\
-1,06 \pm 0,18\end{array}$ & $\begin{array}{l}-1,65 \pm 0,08 \\
-1,32 \pm 0,38 \\
-2,09 \pm 0,43 \\
-1,26 \pm 0,22 \\
-0,88 \pm 0,24\end{array}$ & $\begin{array}{l}-1,62 \pm 0,06 \\
-1,22 \pm 0,30 \\
-1,01 \pm 0,40 \\
-1,08 \pm 0,17 \\
-1,04 \pm 0,20\end{array}$ & $\begin{array}{l}1 \\
1 \\
1 \\
1 \\
1\end{array}$ & $\begin{array}{l}1 \\
1 \\
1 \\
1 \\
1\end{array}$ & $\begin{array}{l}1 \\
1 \\
1 \\
1 \\
1\end{array}$ \\
\hline $\begin{array}{l}\text { \% de récupération } \\
\text { dans le caillé }\end{array}$ & & & & & & \\
\hline $\begin{array}{l}\text { - Matière brute } \\
\text { - NT } \\
\text { - Matière grasse } \\
\text { - EST } \\
\text { - ESD }\end{array}$ & $\begin{array}{l}20,24 \pm 0,30 \\
73,51 \pm 0,58 \\
96,05 \pm 0,60 \\
56,49 \pm 0,53 \\
38,15 \pm 0,37\end{array}$ & $\begin{array}{l}20,22 \pm 0,34 \\
75,39 \pm 0,55 \\
95,97 \pm 0,56 \\
56,28 \pm 0,56 \\
38,80 \pm 0,55\end{array}$ & $\begin{array}{l}20,85 \pm 0,25 \\
76,41 \pm 0,42 \\
97,23 \pm 0,47 \\
57,93 \pm 0,42 \\
39,60 \pm 0,38\end{array}$ & $\begin{array}{l}\text { ! } \\
* \\
\text { ' } \\
\text { I }\end{array}$ & $\begin{array}{l}1 \\
1 \\
1 \\
* \\
1\end{array}$ & $\begin{array}{c}\text { l } \\
* * * \\
! \\
* \\
* *\end{array}$ \\
\hline
\end{tabular}

(1) / : non significatif $(P>5 \%) ;{ }^{\star}:$ : significatif à $5 \% ;{ }^{* *}$ : significatif à $1 \% ;{ }^{* * *}$ : significatif à $0,1 \%$.

(1) /: non-significant ( $P>5 \%$ ); ": significant at 5\%; "*: significant at $1 \%$; "** : significant at $0.1 \%$. 
neurs en matière grasse du lactosérum équivalentes entre les génotypes).

Les bilans "entrées-sorties» des principaux constituants ne sont pas influencés par les variants génétiques de la $\beta$-Lg. Les pertes de caillés sur les grilles d'égouttage qui expliquent les bilans négatifs sur la matière grasse, l'azote total et l'extrait sec total, sont donc équivalentes quel que soit le génotype considéré. Ce résultat est en concordance avec l'absence de différences significatives entre génotypes sur l'aptitude à la coagulation des laits et notamment sur la fermeté des gels.

Les pourcentages de récupération des principaux constituants du lait dans le caillé confirment les résultats précédents et notamment la rétention de l'azote total et de l'extrait sec dégraissé en faveur de l'allèle B. Marziali et Ng-Kwai-Hang (1986b), travaillant sur des fabrications de type Cheddar réalisées au laboratoire, ont de même constaté que les fromages BB pour la $\beta$-Lg présentaient une meilleure rétention des protéines. Ils montrent aussi une meilleure rétention des matières grasses et de la matière brute, ce que nous ne constatons pas à partir de nos fabrications de fromages à pâte molle.

En résumé, la présence du variant $B$ de la $\beta$-Lg est associée à un rapport caséines/NT du lait plus élevé qui se répercute essentiellement sur la répartition caillé/sérum des composants azotés (meilleure récupération des matières azotées totales et de l'EST dans les caillés $\mathrm{BB})$. Ces effets sont sans conséquence sur l'aptitude fromagère (critères de coagulation, bilans fromagers). La position de l'hétérozygote est variable suivant le paramètre considéré; bien situé entre $A A$ et $B B$ pour les critères protéiques, il est inférieur aux 2 homozygotes pour les paramètres liés à la matière grasse.

\section{Influence des variants génétiques de la $\kappa$-caséine}

\section{Composition des laits et aptitude à la coagulation (tableau VII)}

La composition azotée du lait est fortement influencée par les variants génétiques de la $\kappa-\mathrm{Cn}$ : les laits de génotype BB ont une teneur en matières azotées totales (NT) plus élevée $(+1,49 \mathrm{~g} / \mathrm{kg})$ avec un taux d'azote non caséinique (NS) comparable à celui des laits de génotype AA. Par conséquent, le taux de caséine et le rapport caséines/NT sont plus élevés dans le cas des laits de génotype BB (respectivement $+1,61 \mathrm{~g} / \mathrm{kg}$ et $+1,3 \%$ ). Les laits hétérozygotes occupent une position intermédiaire. Ces effets sont confirmés par le taux de matières protéiques $(+1,26 \mathrm{~g} / \mathrm{kg}$ en faveur du lait BB).

Les autres critères de composition du lait (matière grasse, calcium total, extrait sec total et $\mathrm{pH}$ ) ne sont pas influencés par les variants de la $k-\mathrm{Cn}$. II faut cependant signaler que la teneur en matières azotées totales, plus élevée pour les laits de génotype $B B$, se répercute très peu sur l'extrait sec total $(+0,19 \mathrm{~g} / \mathrm{kg})$ du fait d'un taux de matière grasse plus faible $(-1,2 \mathrm{~g} / \mathrm{kg})$ mais non significatif.

L'aptitude à la coagulation du lait est largement influencée par les variants génétiques de la $\kappa-\mathrm{Cn}$ : à $\mathrm{pH}$ et taux de calcium non significativement différents, les laits de génotype BB ont un temps de coagulation et un temps de raffermissement plus courts (respectivement $-3,61$ min soit $-24 \%$ et $-7,02$ min soit $-54 \%$ ) avec une fermeté maximale du gel bien supérieure $(+11,77 \mathrm{~mm}$ soit $+37 \%)$ par rapport aux laits de génotype $A A$; la position des laits hétérozygotes est là encore intermédiaire 
Tableau VII. Comparaison des génotypes de la $\kappa$-caséine et influence sur les paramètres de composition du lait et d'aptitude à la coagulation (moyenne \pm écart type à la moyenne).

Comparison between $\mathrm{k}$-Cn genotypes and influence on milk composition and coagulation properties (mean \pm standard deviation from the mean).

\begin{tabular}{|c|c|c|c|c|c|c|}
\hline & \multicolumn{3}{|c|}{$\kappa$ - caséine } & \multicolumn{3}{|c|}{$\begin{array}{c}\text { Test de comparaison des } \\
\text { moyennes (1) }\end{array}$} \\
\hline & $\begin{array}{l}\text { génotype AA } \\
\text { (31 observ) }\end{array}$ & $\begin{array}{l}\text { génotype AB } \\
\text { ( } 23 \text { observ }) \\
\end{array}$ & $\begin{array}{l}\text { génotype BB } \\
(29 \text { observ ) }\end{array}$ & ANAB & $A B / B B$ & $A \mathrm{~A} B \mathrm{~B}$ \\
\hline \multicolumn{7}{|l|}{$\frac{\text { Composition }}{\text { azotée du lait }}$} \\
\hline - NT & $32,69 \pm 0,34$ & $33,19 \pm 0,37$ & $34,18 \pm 0,40$ & I & 1 & $* *$ \\
\hline $\begin{array}{r}\text { - Matières protéiques } \\
(\mathrm{g} / \mathrm{kg})\end{array}$ & $30,82 \pm 0,34$ & $31,22 \pm 0,36$ & $32,08 \pm 0,40$ & 1 & 1 & $*$ \\
\hline - Caséine $\quad(\mathrm{g} / \mathrm{kg})$ & $25,62 \pm 0,32$ & $26,28 \pm 0,36$ & $27,23 \pm 0,36$ & 1 & 1 & $* *$ \\
\hline - NS $\quad(\mathrm{g} / \mathrm{kg})$ & $7,07 \pm 0,12$ & $6,92 \pm 0,14$ & $6,95 \pm 0,14$ & 1 & I & I \\
\hline$-\frac{\text { Caséines }}{N T}$ & $78,34 \pm 0,37$ & $79,13 \pm 0,43$ & $79,64 \pm 0,36$ & I & I & * \\
\hline \multicolumn{7}{|l|}{$\begin{array}{l}\text { Autres paramètres } \\
\text { de composition }\end{array}$} \\
\hline - Matière grasse $(\mathrm{g} / \mathrm{kg})$ & $40,8 \pm 1,1$ & $40,9 \pm 0,8$ & $39,6 \pm 0,9$ & I & 1 & 1 \\
\hline - Calcium total $(\mathrm{g} / \mathrm{kg})$ & $1,31 \pm 0,04$ & $1,33 \pm 0,04$ & $1,32 \pm 0,03$ & 1 & 1 & l \\
\hline - EST $\quad(\mathrm{g} / \mathrm{kg})$ & $127,87 \pm 1,39$ & $128,70 \pm 0,82$ & $128,06 \pm 1,15$ & I & 1 & I \\
\hline$-p H$ & $6,61 \pm 0,01$ & $6,62 \pm 0,01$ & $6,62 \pm 0,01$ & 1 & I & 1 \\
\hline \multicolumn{7}{|l|}{$\begin{array}{l}\text { Paramètres de } \\
\text { coagulation }\end{array}$} \\
\hline - temps de coagulation $\underset{(\min )}{-}$ & $14,94 \pm 0,76$ & $11,90 \pm 0,67$ & $11,33 \pm 0,44$ & $* *$ & 1 & $* * *$ \\
\hline $\begin{array}{c}\text { - temps de raffermisse } \\
\text { ment du gel } \quad(\mathrm{min})\end{array}$ & $13,10 \pm 1,17$ & $7,71 \pm 0,53$ & $6,08 \pm 0,34$ & $* * *$ & * & $* * *$ \\
\hline $\begin{array}{r}\text { - temps pour atteindre } \\
\text { la fermeté maximale } \\
(\mathrm{min})\end{array}$ & $32,57 \pm 1,59$ & $33,46 \pm 2,15$ & $32,38 \pm 1,39$ & 1 & I & 1 \\
\hline $\begin{array}{c}\text { - fermeté maximale } \\
\text { du gel } \quad(\mathrm{mm})\end{array}$ & $31,65 \pm 1,05$ & $38,68 \pm 0,99$ & $43,42 \pm 1,00$ & $* * *$ & $* *$ & $* * *$ \\
\hline
\end{tabular}

(1) /: non significatif $(P>5 \%) ;{ }^{*}$ : significatif à $5 \% ;{ }^{* *}$ : significatif à $1 \% ;{ }^{* * *}$; significatif à $0,1 \%$.

(1) /: non-significant ( $P>5 \%)$; ": significant at $5 \%$; **: significant at $1 \%$; *** : significant at $0.1 \%$.

mais plus proche de l'homozygote BB. Ces effets sont largement confirmés sur la race Pie Noire (Losi et al, 1973 et 1975; Mariani et al, 1976; Schaar, 1984; Marziali et Ng-Kwai-Hang, 1986b) ou sur d'autres races bovines comme la Brune des Alpes (Losi et Mariani, 1984) et la Modenese (Mariani et Leoni, 1985).

Dans notre étude, la meilleure aptitude à la coagulation des laits porteurs du va- 
riant $B$ est en partie expliquée par une composition azotée plus favorable : la figure 1 montre que la relation entre le taux de caséine et la fermeté maximale des gels est d'autant plus significative que le lait est porteur du variant B (le coefficient de corrélation évoluant dans le sens $B B$ > $A B>A A$ ). Par ailleurs, à taux de caséine identique, les laits porteurs du variant $B$ gardent une aptitude à la coagulation bien supérieure à celles des laits possédant le variant $A$. Des critères plus fins, non étudiés au cours de ce travail, doivent donc être pris en compte dans l'argumentation en faveur d'une meilleure aptitude à la coagulation des laits possédant l'allèle $B$. L'un d'entre eux est la variabilité des proportions relatives des différentes caséines en fonction du polymorphisme génétique de l'une d'entre elles: Kroeker et al (1985) ont montré que la présence de l'allèle $B$ s'accompagne d'une augmentation du taux de $\kappa-\mathrm{Cn}$, sans que le taux de caséine totale du lait soit modifié. Plus précisément encore, Mac Lean et al (1984) ont montré qu'à taux de caséine identique, les laits de génotype BB pour la $\kappa$-Cn sont caractérisés par un taux plus élevé de cette caséine, aux dépens du taux de caséine $\alpha_{\mathrm{s} 1}$ (les taux de caséines $\alpha_{\mathrm{s} 2}$ et $\beta$ n'étant pas modifiés). Ces effets ne sont pas sans répercussions sur la structure micellaire du lait : ainsi, la taille des micelles des laits de génotype $\mathrm{BB}$ pour la $\mathrm{\kappa}-\mathrm{Cn}$ est inférieure à celle des laits AA (Morini et al, 1975). L'augmentation de la proportion relative de $\kappa-\mathrm{Cn}$ dans les laits BB aurait donc pour conséquence une diminution de la taille des micelles, facilitant leur hydratation; l'aptitude à la coagulation par la présure en serait améliorée, le gel obtenu se raffermissant plus vite et présentant une fermeté maximale supérieure (Niki et Arima, 1984). De même, la variation de composi-

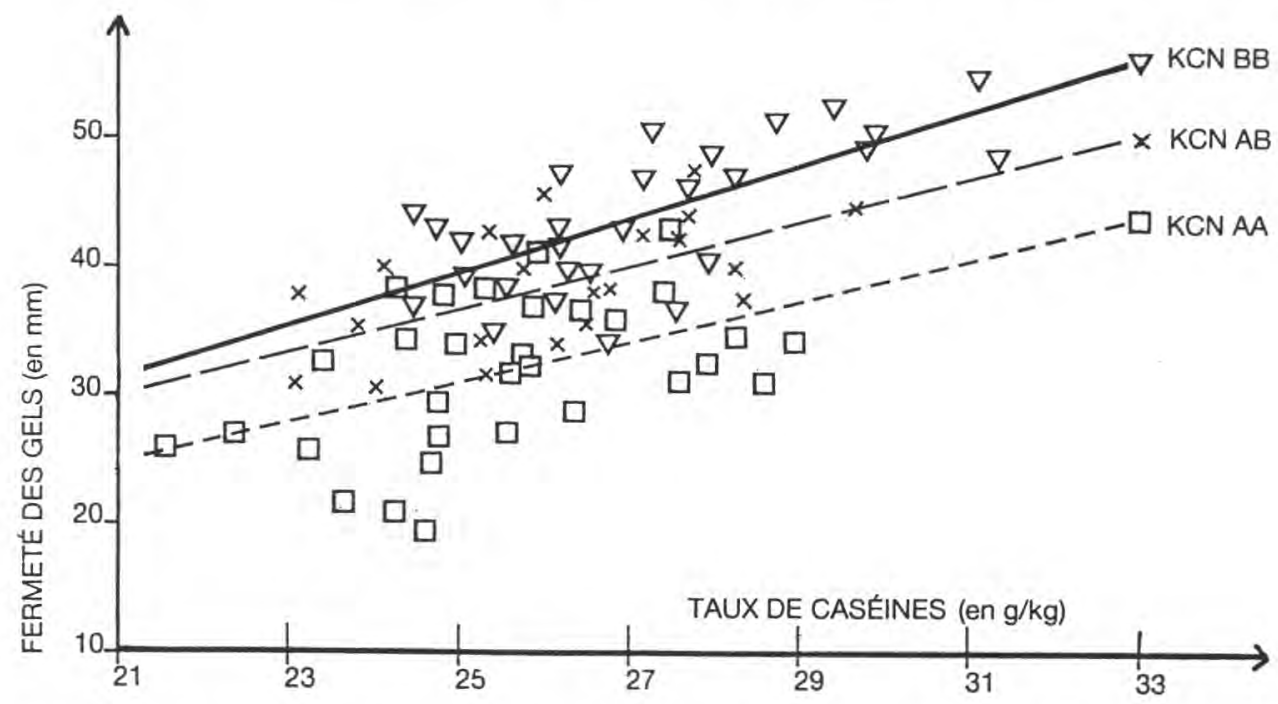

Fig 1. Taux de caséine et fermeté des gels. Influence des variants génétiques de la $\kappa$-caséine. Coef de détermination : $A A$ : 0,2283; $A B: 0,3682 ; B B: 0,5389$; Coef de corrélation : $A A: 0,4778 ; A B$ : 0,$6068 ; \mathrm{BB}: 0,7341$.

Casein ratio and curd firmness: influence of $\kappa$-casein genotypes. Determination coefficient : $A A$ : 0.2283; AB: 0.3682; BB: 0.5389; Correlation coefficient: $A A: 0.4778 ; A B: 0.6068 ; B B: 0.7341$. 
tion en acides aminés de la $k-C n$ selon le variant génétique considéré modifie la charge électrique globale de la protéine et donc la capacité d'agrégation des micelles au cours de la phase de coagulation par la présure (Schaar, 1984).

\section{Résultats des fabrications fromagères (tableau VIII)}

La teneur du caillé en azote total est plus élevée avec le génotype BB qu'avec les génotypes $A A$ et $A B$ (respectivement $+8,65 \mathrm{~g} / \mathrm{kg}$ et $+7,2 \mathrm{~g} / \mathrm{kg}$ ). Ce résultat est confirmé par la teneur en extrait sec dégraissé qui est aussi significativement plus élevée pour le génotype BB.

Ces observations sont expliquées par une composition azotée du lait plus favorable pour le génotype BB (plus d'azote total et un rapport caséines/azote total plus élevé). Les teneurs en matière grasse et en extrait sec total ne sont pas différentes entre les génotypes. Par conséquent, le rapport gras/sec des caillés n'est pas influencé par les variants génétiques de la $\kappa$ Cn. Par contre, l'humidité du fromage dégraissé est significativement plus faible pour le génotype BB $(-0,58 \%)$, ce qui confirme une meilleure aptitude à l'égouttage du caillé pour ce génotype du fait d'une teneur en caséines du lait plus favorable.

La composition du lactosérum ne diffère de façon significative entre les génotypes que pour la matière grasse : $+0,46 \mathrm{~g} / \mathrm{kg}$ $(+62,2 \%)$ pour le génotype $A A$ par rapport au génotype $B B$, I'hétérozygote $A B$ étant intermédiaire. Comme la teneur en matière grasse du lait n'était pas différente entre les génotypes, la perte de matière grasse plus importante dans le lactosérum AA indique une moins bonne aptitude à la rétention du caillé pour ce génotype.

En ce qui concerne les bilans centréessorties", le génotype BB se caractérise par une perte en matière brute égale à 1,46\% accompagnée de faibles pertes de constituants $(-0,22 \%$ pour l'azote total; $-0,21 \%$ pour la matière grasse). Par contre, la présence du génotype $A A$ entraîne une perte de matière brute plus élevée $(-1,76 \%)$ associée à de plus fortes pertes de constituants $(-2,11 \%$ pour l'azote total; $-1,16 \%$ pour la matière grasse). Pour ces critères, I'hétérozygote $A B$ est intermédiaire. L'origine de ces pertes est de deux natures : d'une part l'évaporation (pertes d'eau sans pertes de constituants), d'autre part les pertes de caillé sur les grilles d'égouttage (avec pertes de constituants). A priori, les pertes sous forme d'évaporation sont identiques entre les génotypes du fait des conditions expérimentales. En revanche, les pertes de caillé sur les grilles d'égouttage sont beaucoup plus importantes pour le génotype $A A$, du fait des pertes de constituants significativement plus élevées par rapport au génotype $B B$. Ces résultats s'expliquent par une plus faible fermeté des gels pour le génotype AA.

Enfin, les pourcentages de récupération dans le caillé de l'azote total, de la matière grasse et de l'extrait sec degraissé sont plus élevés en présence du variant $B$ ( $B B$ $>A B>A A$ ), ce qui confirme les résultats précédents.

En somme, l'amélioration des critères de coagulation du lait en présence du variant $B$ se traduit aussi par une meilleure aptitude à la fabrication fromagère de type Camembert en regard de la baisse des pertes de caillé sur les grilles d'égouttage et de la plus grande rétention des constituants dans le caillé (azote et matière grasse). Ces éléments sont aussi avancés par Morini et al (1979) sur une fabrication de Parmesan pour expliquer l'amélioration du rendement fromager en présence du génotype $B B(+0,6 \mathrm{~kg}$ de fromage pour $100 \mathrm{~kg}$ de lait, soit $+8 \%$ ). Dans une fabrication de Cheddar canadien, Marziali et Ng- 
Tableau VIII. Influence des variants génétiques de la $\kappa$-caséine sur les résultats des fabrications fromagères (moyenne \pm écart type à la moyenne).

Influence of genetic variants of $\mathrm{K}-\mathrm{Cn}$ on the cheese-making results (Mean \pm standard deviation from the mean).

\begin{tabular}{|c|c|c|c|c|c|c|}
\hline & \multicolumn{3}{|c|}{$\kappa$ - caséine } & \multicolumn{3}{|c|}{$\begin{array}{c}\text { Test de comparaison des } \\
\text { moyennes (1) }\end{array}$} \\
\hline & $\begin{array}{l}\text { génotype AA } \\
\text { (31 observ) }\end{array}$ & $\begin{array}{l}\text { génotype } A B \\
(23 \text { observ) } \\
\end{array}$ & $\begin{array}{l}\text { génotype BB } \\
(29 \text { observ.) } \\
\end{array}$ & ANAB & $\mathrm{AB} / \mathrm{BB}$ & AA/BB \\
\hline \multicolumn{7}{|l|}{$\begin{array}{l}\text { Composition dy } \\
\text { caillé "24 heures" }\end{array}$} \\
\hline $\begin{array}{lr}\text { - poids } & (\mathrm{g}) \\
\text { - NT } & (\mathrm{g} / \mathrm{kg}) \\
\text { - NS } & (\mathrm{g} / \mathrm{kg}) \\
\text { - matière grasse }(\mathrm{g} / \mathrm{kg}) \\
\text { - E S T } & (\mathrm{g} / \mathrm{kg}) \\
\text { - ES D } & (\mathrm{g} / \mathrm{kg}) \\
\text { - G/S } & (\%) \\
\text { - H.F. } & (\%) \\
\text { - p H } & \end{array}$ & $\begin{array}{r}204,85 \pm 3,15 \\
117,83 \pm 1,17 \\
8,46 \pm 0,21 \\
188,35 \pm 3,98 \\
351,66 \pm 3,29 \\
163,30 \pm 1,36 \\
53,41 \pm 0,64 \\
79,88 \pm 0,13 \\
4,47 \pm 0,03\end{array}$ & $\begin{array}{r}209,27 \pm 2,58 \\
119,28 \pm 1,31 \\
8,37 \pm 0,16 \\
189,74 \pm 2,99 \\
353,08 \pm 2,35 \\
163,35 \pm 1,85 \\
53,69 \pm 0,60 \\
79,85 \pm 0,19 \\
4,49 \pm 0,04\end{array}$ & $\begin{array}{r}208,15 \pm 2,90 \\
126,48 \pm 1,61 \\
8,57 \pm 0,14 \\
186,48 \pm 3,22 \\
354,87 \pm 3,12 \\
168,36 \pm 1,68 \\
52,47 \pm 0,57 \\
79,30 \pm 0,20 \\
4,46 \pm 0,04\end{array}$ & $\begin{array}{l}1 \\
1 \\
1 \\
1 \\
1 \\
1 \\
1 \\
1 \\
1\end{array}$ & $\begin{array}{l}\text { ! } \\
* * * \\
! \\
! \\
! \\
* \\
! \\
1\end{array}$ & $\begin{array}{l}\text { I } \\
* * * \\
! \\
! \\
! \\
\text { ! } \\
* \\
1\end{array}$ \\
\hline \multicolumn{7}{|l|}{$\begin{array}{l}\text { Composition du } \\
\text { lactosérum }\end{array}$} \\
\hline $\begin{array}{lr}\text { - poids } & (\mathrm{g}) \\
- \text { NT } & (\mathrm{g} / \mathrm{kg}) \\
\text { - NS } & (\mathrm{g} / \mathrm{kg}) \\
\text { - matière grasse } & (\mathrm{g} / \mathrm{kg}) \\
\text { - calcium total } & (\mathrm{g} / \mathrm{kg}) \\
\text { - E.S.T } & (\mathrm{g} / \mathrm{kg}) \\
\text { - E.S.D } & (\mathrm{g} / \mathrm{kg})\end{array}$ & $\begin{array}{r}789,27 \pm 3,04 \\
10,04 \pm 0,15 \\
9,78 \pm 0,15 \\
1,20 \pm 0,09 \\
1,05 \pm 0,04 \\
68,09 \pm 0,30 \\
66,89 \pm 0,30\end{array}$ & $\begin{array}{r}786,82 \pm 2,63 \\
9,80 \pm 0,15 \\
9,58 \pm 0,16 \\
0,83 \pm 0,07 \\
1,03 \pm 0,03 \\
67,88 \pm 0,23 \\
67,05 \pm 0,26\end{array}$ & $\begin{array}{r}789,27 \pm 2,89 \\
9,94 \pm 0,15 \\
9,77 \pm 0,16 \\
0,74 \pm 0,05 \\
0,99 \pm 0,03 \\
67,34 \pm 0,32 \\
66,60 \pm 0,31\end{array}$ & $\begin{array}{l}1 \\
1 \\
1 \\
* * \\
1 \\
1 \\
1\end{array}$ & $\begin{array}{l}1 \\
1 \\
1 \\
1 \\
1 \\
1 \\
1\end{array}$ & $\begin{array}{l}1 \\
! \\
1 \\
* * * \\
! \\
1 \\
1\end{array}$ \\
\hline \multicolumn{7}{|l|}{$\begin{array}{l}\text { Bilans } \\
\text { "entrées - sorties" }\end{array}$} \\
\hline $\begin{array}{ll}\text { - matière brute } & (\%) \\
\text { - NT } & (\%) \\
\text { - matière grasse } & (\%) \\
\text { - EST } & (\%) \\
\text { - ES D } & (\%)\end{array}$ & $\begin{array}{r}-1,79 \pm 0,06 \\
-2,11 \pm 0,31 \\
-1,16 \pm 0,15 \\
-1,60 \pm 0,20 \\
-0,89 \pm 0,18\end{array}$ & $\begin{array}{r}-1,62 \pm 0,04 \\
-1,70 \pm 0,34 \\
-0,52 \pm 0,19 \\
-1,20 \pm 0,20 \\
-1,01 \pm 0,15\end{array}$ & $\begin{array}{r}-1,46 \pm 0,04 \\
-0,22 \pm 0,19 \\
-0,21 \pm 0,12 \\
-0,85 \pm 0,14 \\
-0,76 \pm 0,20\end{array}$ & $\begin{array}{l}* \\
! \\
\text { ** } \\
!\end{array}$ & $\begin{array}{c}* \\
* * * \\
1 \\
1 \\
1\end{array}$ & $\begin{array}{c}* * * \\
* * * \\
* * * \\
* * \\
\text { / }\end{array}$ \\
\hline \multicolumn{7}{|l|}{$\begin{array}{l}\% \text { récupération dans } \\
\text { le caillé }\end{array}$} \\
\hline $\begin{array}{l}\text { - matière brute } \\
\text { - NT } \\
\text { - matière grasse } \\
\text { - E.S.T. } \\
\text { - E.S.D. }\end{array}$ & $\begin{array}{l}20,24 \pm 0,31 \\
73,61 \pm 0,54 \\
94,63 \pm 0,56 \\
56,23 \pm 0,54 \\
38,32 \pm 0,39\end{array}$ & $\begin{array}{l}20,65 \pm 0,26 \\
75,03 \pm 0,56 \\
97,09 \pm 0,52 \\
57,29 \pm 0,50 \\
38,80 \pm 0,45\end{array}$ & $\begin{array}{l}20,57 \pm 0,29 \\
76,81 \pm 0,39 \\
97,98 \pm 0,31 \\
57,27 \pm 0,44 \\
39,55 \pm 0,44\end{array}$ & $\begin{array}{l}\text { l } \\
\text { ! } \\
\text { ! } \\
1\end{array}$ & $\begin{array}{l}\text { ! } \\
* \\
1 \\
1 \\
1\end{array}$ & $\begin{array}{c}I_{* * *} \\
* * * \\
!\end{array}$ \\
\hline
\end{tabular}

(1) / : non significatif $(P>5 \%) ;{ }^{*}$ : significatif à $5 \%$; "* : significatif à $1 \%$; *** : significatif à $0,1 \%$.

(1) ): non-significant ( $P>5 \%$ ); ": significant at $5 \%$; "**: significant at $1 \%$; "** : significant at $0.1 \%$. 
Kwai-Hang (1986a) observent également un avantage du génotype BB chiffrable à environ $+4 \%$.

\section{Analyse factorielle discriminante (AFD) et interactions entre les génotypes des 2 protéines}

L'AFD a été établie à partir d'une population statistique divisée en 8 sousensembles disjoints (les 8 groupes de génotypes de la $\beta$ - Lg et de la $\kappa-\mathrm{Cn}$ ) et des paramètres quantitatifs divisés en 6 catégories : composition du lait, paramètres de coagulation, composition du caillé, composition du lactosérum, bilans entrées-sorties et pourcentages de récupération dans le caillé.

Les 2 premiers axes principaux du cercle de corrélation (fig 2) fournissent $62,8 \%$ de l'information $(40,1 \%$ pour l'axe 1 et $22,7 \%$ pour l'axe 2). Une première composante discriminante est déterminée par les principaux critères de rendement fromager. Les variables qui déterminent le mieux l'axe 1 sont respectivement le taux de caséine (CAS), la fermeté maximale des gels (AMA) et le bilan matière grasse (BMG); les critères de fabrication fromagère les plus corrélés à la première composante discriminante sont les pourcentages de récupération des matières azotées totales (\% PM1) et de la matière grasse (\% M1). Concernant les paramètres d'aptitude à la coagulation, on constate fort logiquement la très nette opposition entre la fermeté maximale des gels (AMA) d'une part et les temps de coagulation et de raffermissement du gel (TC et TA2) d'autre part. L'axe 1 est par conséquent principalement déterminé par les critères influencés significativement par les variants génétiques de la $\mathrm{k}-\mathrm{Cn}$.
L'axe 2 semble, quant à lui, plus difficile à définir. Un groupe de 4 variables apparaît néanmoins : POI, NSK, NSF, NSS (cette dernière masquée par NSF). Trois de ces variables représentent respectivement l'azote soluble du lait, du caillé et du lactosérum. On peut ainsi supposer que ce nouveau critère définit la deuxième composante discriminante. Quant à la variable restante $\mathrm{POI}$, elle caractérise le poids du sérum sans corrélation avec NSK, NSF et NSS. L'axe 2 serait donc essentiellement déterminé par les critères d'azote soluble significatifs dans l'analyse de l'influence des variants génétiques de la $\beta$ - Lg.

La figure 3 présente la projection des 83 observations dans le plan et la position des 8 centres de gravité (G1, G2, ..., G8) correspondant aux 8 groupes de génotypes étudiés; elle permet ainsi d'estimer les interactions entre les variants génétiques des 2 protéines. On constate tout d'abord une bonne différenciation des groupes suivant les variants, aussi bien pour la $\beta$ - Lg que pour la $\kappa-\mathrm{Cn}$. La forme géométrique particulière obtenue confirme la relation existant entre les variants génétiques et les variables corrélées avec les axes 1 et 2; ainsi, pour les 3 génotypes $A A, A B, B B$ de chacune des protéines, on obtient 3 bandes successives, globalement parallèles, corrélées à l'axe 1 pour la $\kappa-\mathrm{Cn}$ et à l'axe 2 pour la $\beta$ - $\mathrm{Lg}$. Les hétérozygotes $A B$ se situent dans chaque cas en position intermédiaire. Les variants génétiques de la $\kappa$-Cn exerçant les effets les plus marqués, l'analyse a été complétée à partir du tableau d'appartenance (tableau IX). Le tableau souligne bien l'antagonisme entre les génotypes AA et BB de la $\mathrm{k}$ - $\mathrm{C} n$ puisque les individus $B B$ de cette protéine ne sont jamais affectés à des individus $A A$, et inversement. Sur 60 laits homozygotes AA ou BB, $76,7 \%$ sont bien affectés. Par contre, concernant les hétérozygotes, leur affectation est très dispersée $(26,1 \%$ de bien classés). 


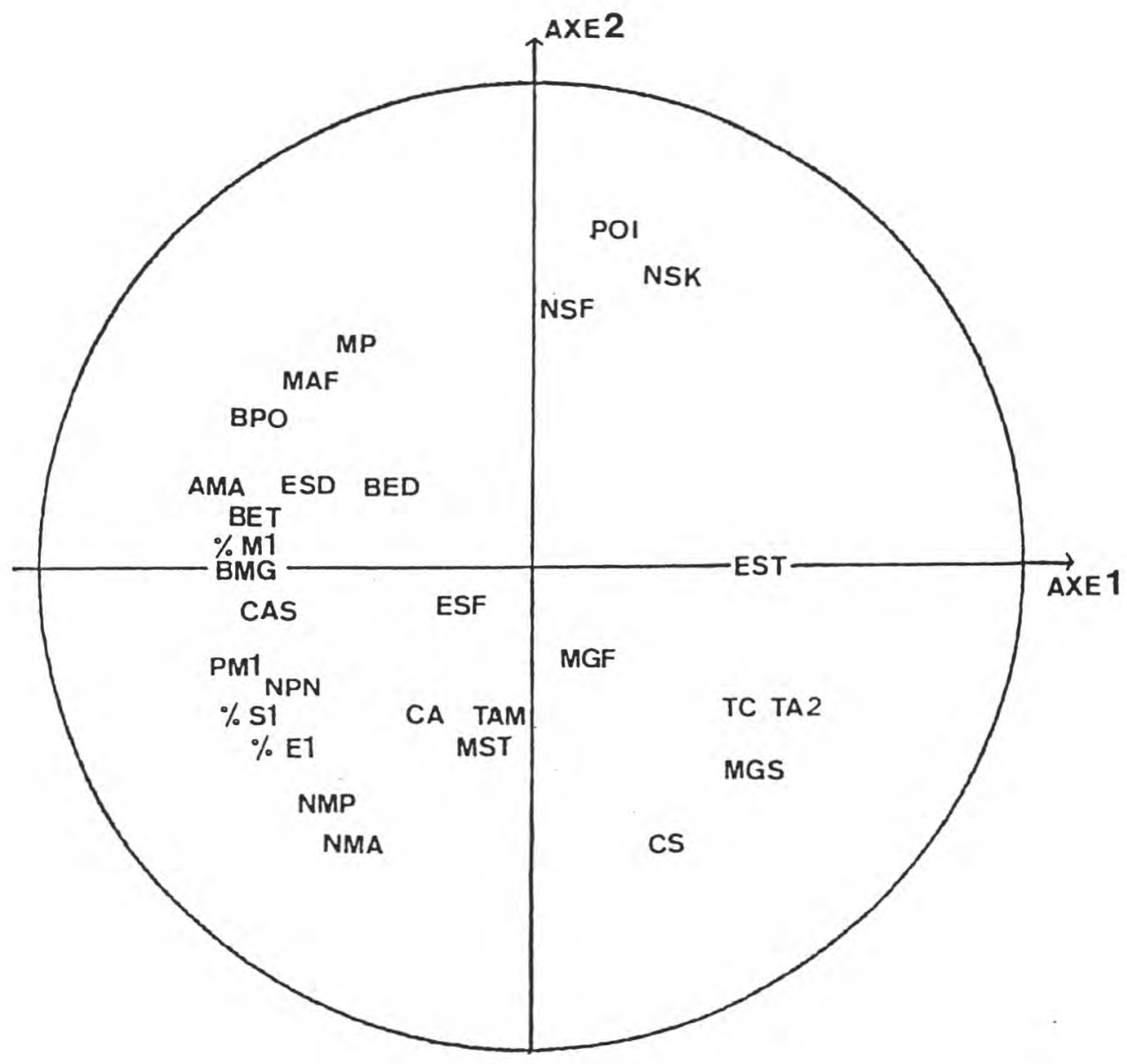

Fig 2. Analyse factorielle discriminante. Cercle des corrélations. Axe 1: horizontal. Axe 2: vertical. Liste des variables: Composition du lait: MP: matières protéiques $(\mathrm{g} / \mathrm{kg})$; CAS: taux de caséines $(\mathrm{g} / \mathrm{kg})$; NSK: azote soluble mesuré par Kjeldahl $(\mathrm{g} / \mathrm{kg})$; NPN: azote non protéique $(\mathrm{g} / \mathrm{kg})$; NMA: nombre caséinique par rapport aux matières azotées totales ( $\mathrm{g} / \mathrm{kg}$ ); NMP: nombre caséinique par rapport aux MP; CA: calcium total $(\mathrm{g} / \mathrm{kg})$; MST: matière sèche totale $(\mathrm{g} / \mathrm{kg})$. Paramètres de coagulation du lait : TC: temps de coagulation (min); TA2: temps de raffermissement (min); TAM: temps avec fermeté maximale (min); AMA: fermeté maximale $(\mathrm{mm})$. Composition du caillé : MGF: matière grasse $(\mathrm{g} / \mathrm{kg})$; MAF: matières azotées totales $(\mathrm{g} / \mathrm{kg})$; NSF: azote soluble $(\mathrm{g} / \mathrm{kg})$ dégraissé; ESF: extrait sec total $(\mathrm{g} / \mathrm{kg})$; ESD: extrait sec dégraissé $(\mathrm{g} / \mathrm{kg})$. Composition du lactosérum : POI : poids $(\mathrm{g})$; MGS: matière grasse $(\mathrm{g} / \mathrm{kg})$; NSS: azote soluble $(\mathrm{g} / \mathrm{kg})$; CS: calcium $(\mathrm{g} / \mathrm{kg})$; EST: extrait sec total $(\mathrm{g} / \mathrm{kg})$. Bilans fromagers "entrée-sortie»: PBO: bilan poids (g); BMG: bilan matière grasse (g); BET: bilan extrait sec total (g); BED: bilan extrait sec dégraissé $(\mathrm{g})$. Pourcentages de récupération dans le caillé "24 h»: $\% \mathrm{P} 1$ : pourcentage de récupération de la matière brute; \%M1: pourcentage de récupération de la matière grasse; PM1: pourcentage de récupération des MAT; \%E1: pourcentage de récupération de l'extrait sec total; \%\$1: pourcentage de récupération de l'extrait sec dégraissé.

Discriminating factorial analysis: correlation circle. Axis 1: horizontal. Axis 2: vertical. 
Tableau IX. Analyse factorielle discriminante. Tableau d'appartenance (génotypes de la $\kappa-C n$ ). Discriminating factorial analysis: membership table ( $\kappa$-Cn genotypes).

\begin{tabular}{crrrr} 
Appartenance & \multicolumn{4}{c}{ Affectation } \\
\cline { 2 - 5 } & $A A$ & $A B$ & $B B$ & Total \\
\hline AA & 23 & 8 & 0 & 31 \\
AB & 9 & 6 & 8 & 23 \\
BB & 0 & 6 & 23 & 29 \\
Total & 32 & 20 & 31 & 83 \\
\hline
\end{tabular}

L'AFD permet de conclure à un effet additif de l'influence des variants génétiques de la $\beta$ - $\mathrm{Lg}$ et de la $\kappa-\mathrm{Cn}$; une classification des groupes génotypiques est permise à partir de leurs centres de gravité, en prenant les coordonnées des individus sur l'axe 1, déterminé par les principales composantes liées aux variables fromagères (fig 3); on obtient alors le classement suivant (du moins bon au meilleur) : $A A-A A$; $A B-A A$; $B B-A A ; A A-A B$; BB-AB; $A A-B B$; $A B-B B ; B B-B B$ (respectivement $\beta-L g$ et $\kappa$ $\mathrm{Cn})$.

\section{CONCLUSION}

Cette étude confirme la meilleure aptitude fromagère des laits possédant l'allèle $B$ de la $\kappa-\mathrm{C} n$ et dans une moindre mesure, l'allèle $B$ de la $\beta$-Lg.

Pour la plupart des critères étudiés, elle permet de classer les génotypes de chacune des protéines dans l'ordre $A A<A B<$ $B B$. La supériorité du génotype $B B$ de la $\beta$ Lg s'exprime principalement sur le taux de caséines du lait $(+4,7 \%$ par rapport au gé- notype $A A$ ) et sur la rétention des matières azotées totales dans le caillé $(+2,9 \%)$. L'influence du polymorphisme génétique de la $\kappa-C n$ est beaucoup plus marquée : le génotype BB confère au lait une meilleure aptitude à la coagulation (réduction du temps de coagulation de $24 \%$ par rapport à l'homozygote $\mathrm{AA}$, augmentation de $37 \%$ de la fermeté maximale des gels), ce que nous justifions en partie par un taux de caséines plus élevé dans les laits $\mathrm{BB}(+1,61$ $\mathrm{g} / \mathrm{kg}$ ). Cependant, à taux de caséines identiques, l'aptitude à la coagulation reste supérieure en présence du variant $B$. En fabrication de fromage à pâte molle, le génotype BB de la $\kappa-C n$ est par ailleurs associé à une meilleure composition azotée des caillés $(+3,2 \%$ pour l'azote total), une humidité du fromage dégraissé inférieure $(-0,58 \%)$ et des pertes de matière grasse dans le lactosérum plus faibles. Ceci se traduit par une meilleure rétention des composants nobles du lait dans les caillés BB. La fermeté très supérieure des gels $B B$ se répercute sur les bilans entréessorties par une limitation des pertes de caillé sur les grilles d'égouttage.

Le traitement des données par analyse factorielle discriminante souligne le caractère additif des effets des variants génétiques de la $\beta-\mathrm{Lg}$ et de la $\kappa-\mathrm{Cn}$. Elle illustre les effets de synergie entre les variants et traduit bien l'intérêt de la prise en compte de façon combinée des polymorphismes génétiques des lactoprotéines. Ainsi, au cours de ce travail, nous nous sommes limités à l'étude de 2 d'entre elles seulement, préférant l'approche comparative entre génotypes de chaque protéine d'une part, et entre combinaisons génotypiques inter-protéines d'autre part. Nous avons donc mis en œuvre un protocole expérimental privilégiant la méthodologie d'échantillonnage des animaux et la multiplication des fabrications fromagères (autorisant les traitements statistiques appro- 


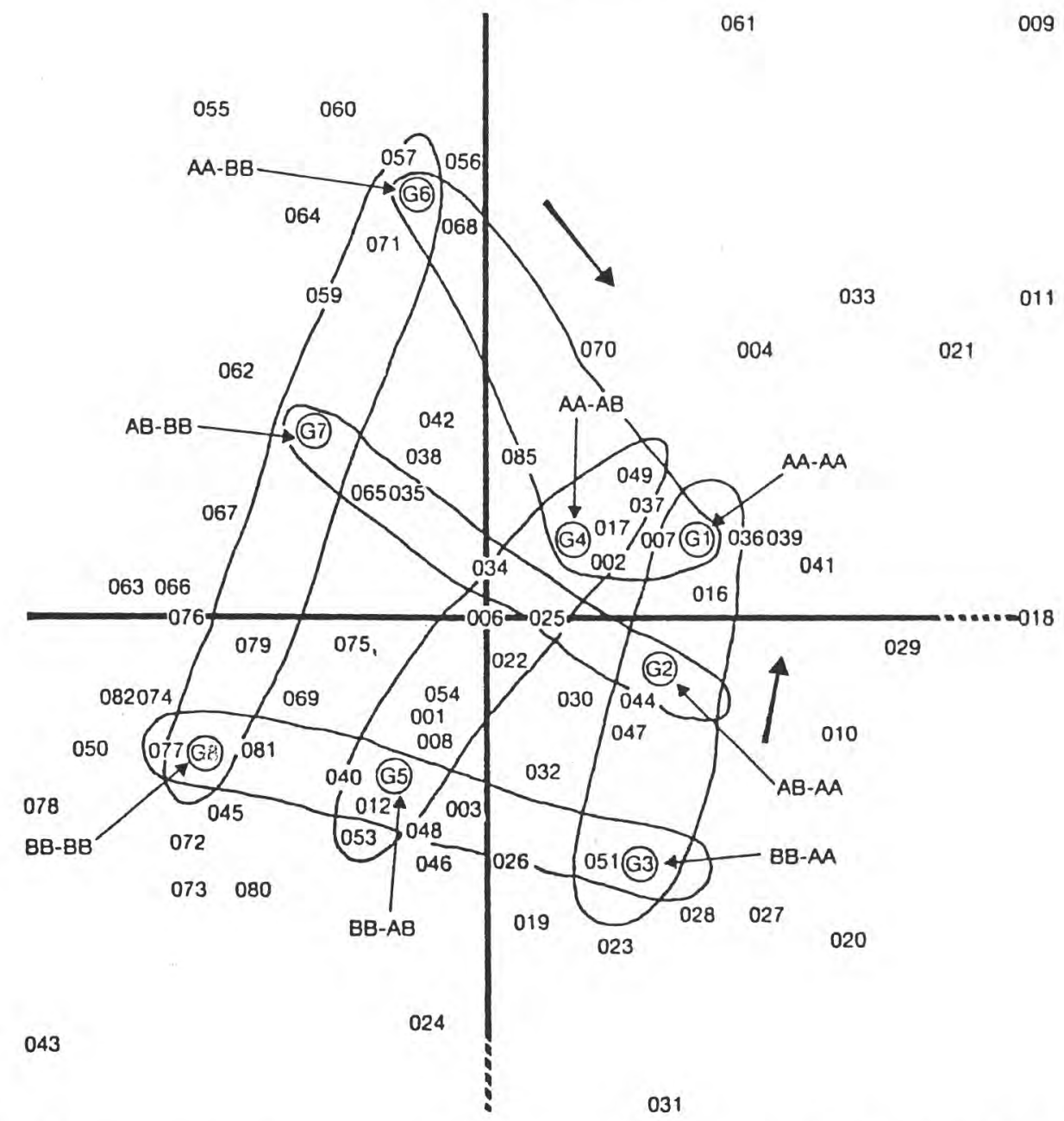

Fig 3. Analyse factorielle discriminante. Interactions entre les variants génétiques de la $\beta$ - Lg et de la $\kappa-C n$. Axe 1: horizontal. Axe 2: vertical.

Discriminating factorial analysis: interactions between genetic variants of $\beta-\operatorname{Lg}$ and $\kappa-C n$. Axis 1 : horizontal. Axis 2: vertical.

priés). II convient cependant de relativiser les résultats obtenus en fonction de certains paramètres non mesurés lors de cette étude. Ce sont :

1) les effets sur la composition du lait et son aptitude fromagère du polymorphisme génétique des autres protéines, et notam- ment ceux de la $\beta-\mathrm{Cn}$, de plus en plus étudiés (Feagan et al, 1972; Corradini et Bergamaschi, 1974; Marziali et Ng-KwaiHang, 1986b);

2) les phénomènes de liaisons génétiques entre les loci de structure des différentes caséines. Ces liaisons sont maintenant 
bien caractérisées (Grosclaude et al, 1964; $1965 ; 1978)$ et se traduisent par une association non aléatoire des allèles de ces loci. II s'ensuit un fort déséquilibre dans les fréquences des haplotypes des 3 caséines principales $\left(\alpha_{\mathrm{s} 1}, \beta, \kappa\right)$ rencontrées dans les principales races bovines (Grosclaude, 1988). Compte tenu des effets du polymorphisme génétique d'une des caséines sur les proportions relatives de l'ensemble des caséines (Mc Lean et al, 1984; Kroeker et al, 1985) et du fait des liaisons génétiques, il faudrait considérer, non pas l'allèle d'une caséine, mais l'haplotype formé par l'association génétique des différentes caséines;

3) les conséquences du polymorphisme génétique d'une protéine, évaluées en terme de composition et de structure fines du lait (proportions relatives des caséines, constitution et taille micellaires, taux de calcium et de phosphore colloïdaux), et leurs répercussions sur l'aptitude à la coagulation (Lenoir et Schneid, 1984).

L'intérêt économique de la prise en compte d'un effet variant est évident, si l'on considère les avantages que présentent, en terme d'aptitude fromagère, les laits de races bovines à fréquence élevée d'allèles favorables, notamment l'allèle B pour la $\kappa$ $\mathrm{Cn}$ et la $\beta-\mathrm{Lg}$. Cependant, cette étude illustre qu'à l'intérieur même d'une race, et à taux de caséines identiques, l'identification des variants génétiques des lactoprotéines peut constituer un outil de diagnostic en vue de la sélection des animaux potentiellement intéressants pour la transformation fromagère.

\section{REMERCIEMENTS}

Ce travail a été financé par le GIE Lait-Viande des Pays-de-la-Loire sur des crédits Onilait avec la participation de l'ITEB. II a bénéficié de l'appui d'un comité de surveillance et d'orientation composé de représentants de l'INRA, de la
DRAF, de l'ITEB, des industries fromagères, de I'EDE, de la FRPL, du GIE et l'ESA.

Les auteurs remercient vivement B Ribadeau-Dumas et $L$ Vassal (INRA Jouy-en-Josas; laboratoire de recherches en technologie laitière), F Grosclaude et MF Mahé (INRA-Jouyen-Josas; laboratoire de génétique biochimique) pour leurs conseils et appuis méthodologiques.

\section{RÉFÉRENCES}

AFNOR-ISTV (1986) Contrôle de la qualité des produits laitiers. $3^{\theta}$ ed AFNOR, ISTV

Alais C (1984) Science du lait. Principe des techniques laitières, $4^{\circ}$ ed SEPAIC, Paris

Aschaffenburg R, Drewry J (1959) New procedure of the routine determination of the various non casein proteins in milk. $X V^{B}$ Congr Int Lait 3, sect 5, 1631-1637

Bell K, Mc Kenzie HA, Shaw DC (1968) Amino acid composition and peptide maps of $\beta$ lactoglobulin variants. Biochim Biophys Acta 154, 284-294

CNIEL (1990) L'Économie laitière en chiffres. CNIEL, Paris

Corradini C, Bergamaschi E (1974) Influenza di alcune varianti genetiche sul comportamento della caseina in processi enzimatici. Sci Tec Latt Casearia 25, 202-213

Feagan JT, Bailey LF, Hehir AF, Mac Lean DM, Ellis NJS (1972) Coagulation of milk proteins. 1. Effects of genetic variants of milk proteins on rennet coagulation and heat stability of normal milk. Aust J Dairy Technol 27, 129134

Grappin R (1976) Guide pour l'évaluation des méthodes d'analyse de routine. Lait 56,608 621

Grappin R, Jeunet R (1971) Essais de l'appareil "Compteur Coulter" utilisé pour la détermination du nombre de cellules totales des laits de troupeaux. Lait 51, 273-293

Gripon JC, Desmazeaud MJ, Le Bars D, Bergère JL (1975) Étude du rôle des microorganismes et des enzymes au cours de la maturation des fromages. II. Influence de la présure commerciale. Lait 55, 502-516

Grosclaude F (1988) Le polymorphisme génétique des principales lactoprotéines bovines. 
Relations avec la quantité, la composition et les aptitudes fromagères du lait. INRA Prod Anim 1, 5-17

Grosclaude F, Garnier J, Ribadeau-Dumas B, Jeunet R (1964) Étroite dépendance des loci contrôlant le polymorphisme des caséines $\alpha$ et $\beta$. CR Hebd Séances Acad Sci Paris 259, 1569-1571

Grosclaude F, Pujolle J, Ribadeau-Dumas B (1965) Déterminisme génétique des caséines $\kappa$ du lait de vache; étroite liaison du locus $\kappa-C n$ avec les loci $\alpha_{s 1}-C n$ et $\beta-C n$. $C R$ Hebd Séances Acad Sci Paris 261, 5229. 5232

Grosclaude F, Mahé MF, Mercier JC, RibadeauDumas B (1972) Localisation des substitutions d'acides aminés différenciant les variants $A$ et $B$ de la caséine $\kappa$ bovine. Ann Génét Sél Anim 4, 515-521

Grosclaude F, Joudrier P, Mahé MF (1978) Polymorphisme de la caséine $\alpha_{\mathrm{s} 2}$ bovine : étroite liaison du locus $\alpha_{\mathrm{s} 2}-\mathrm{Cn}$ avec les loci $\alpha_{\mathrm{s} 1}-\mathrm{Cn}, \beta-\mathrm{Cn}$ et $\kappa-\mathrm{Lg}$; mise en évidence d'une délétion dans le variant $\alpha_{s 2}-C n D$. Ann Génét Sél Anim 10, 313-327

Institut Technique du Gruyère (1984) Mesure du temps de coagulation et de la fermeté du caillé. Étude comparative de trois appareils : le Formagraph, le Thromboélastograph, le Gélograph. Etude Z0 84.01.B

Kroeker EM, Ng-Kwai-Hang KF, Hayes JF, Moxley JE (1985) Effects of environmental factors and milk protein polymorphism on composition of casein fraction in bovine milk. J Dairy Sci 68, 1752-1757

Lenoir J, Schneid N (1984) L'aptitude du lait à la coagulation par la présure. In: Le Fromage (Eck A, ed) $2^{\circ}$ ed, Technique et Documentation Lavoisier, Paris, 139-150

Losi G, Mariani P (1984) Significato tecnologico del polimorphismo delle proteine del latte nella caseificazione a formaggio grana. Ind Latte 20, 23-53

Losi G, Capella P, Castagnetti GB, Grazia L, Zambonelli C, Mariani P, Russo V (1973) Influenza delle varianti genetiche della caseina $\kappa$ sulla formazione $\theta$ sulle caratteristiche delle cagliata. Sci Tec Alimenti 3, 373-376

Losi G, Castagnetti GB, Morini D (1975) Importanza delle varianti genetiche delle proteine del latte per l'industria latterio - casearia. Mondo Latte 29, 727-739

Mc Lean DM, Graham ERB, Ponzoni RW (1984) Effects of milk protein genetic variants on milk yield and composition. J Dairy Res 51, 531-546

Mariani P (1985) Osservazioni sull'indice di caseina del latte di vacche frisone. Sci Tec Latt Casearia 36, 191-209

Mariani P, Leoni M (1985) II tempo di coagulazione del latte in rapporto alle varianti genetiche delle caseine $\beta$ е к. Ann Fac Med Vet Univ Parma 5, 185-195

Mariani P, Losi G, Russo V, Castagnetti GB, Grazia L, Morini D. Fossa E (1976) Prove di caseificazione con latte caratterizatto dalle varianti $A$ e $B$ della $\kappa$ - caseina nella produzione del formaggia parmigiano-reggiano. Sci Tec Latt Casearia 27, 208-277

Mariani P, Morini D, Losi G, Castagnetti GB, Fossa E, Russo V (1979) Ripartizione delle frazioni azotate del latte in vacche caratterizzate da genotipo diverso nel locus $\beta$ lattoglobulina. Sci Tec Latt Casearia 30, 153176

Marziali AS, Ng-Kwai-Hang KF (1986a) Relationships between milk protein polymorphisms and cheese yielding capacity. J Dairy Sci 69, 1193-1201

Marziali AS, Ng-Kwai-Hang KF (1986b) Effects of milk composition and genetic polymorphism on cheese composition. $J$ Dairy Sci 69, 2533-2542

Mietton B (1986) Les rendements en fromagerie. Éléments de méthodologie pour une meilleure détermination et utilisation des données. Rev ENIL 104, 6-16

Mietton B (1987) La préparation des laits de fromagerie en technologie pâtes molles. Rev ENIL 113, 22-33

Morini D, Losi G, Castagnetti GB, Benevelli M, Resmini P, Volonterio G (1975) L'influenza delle varianti genitiche della $\kappa$ - caseina sulla dimensione della micelle caseniche. Sci Tec Latt Casearia 26, 437-444

Morini D, Losi G, Castagnetti GB, Mariani P (1979) Prove di caseificazione con latte caraterizzato della varianti $A$ e $B$ della $\kappa$-caseina: rilievi sul formaggio stagionato. Sci Tec Latt Casearia 30, 243-262 
Morini D, Castagnetti GB, Chiavari C, Grazia L, Losi G, Davioli R; Bosi P (1982) Prova di caseificazione con latte caratterizzato dalle varianti $A$ e $B$ della $\beta$ - lattoglobulina nella produzione del formaggio Parmigiano Reggiano. Sci Tec Latt Casearia 33, 475-492

Ng-Kwai-Hang KF, Hayes JF, Moxley JE, Monardes HG (1984) Association of genetic variants of casein and milk serum proteins with milk, fat and protein production by dairy cattle. J Dairy Sci 67, 835-840
Niki R, Arima S (1984) Effects of size of casein micelle on firmness of rennet curd. Jpn $J$ Zootech Sci 55, 409-415

Schaar J (1984) Effects of casein genetic variants and lactation number on the renneting properties of individual milk. J Dairy Res 51 , 397-406

Wake RG, Baldwin RL (1961) Analysis of casein fractions by zone electrophoresis in concentrated urea. Biochim Biophys Acta 47, 225239 